\title{
The effectiveness of traditional methods and altered auditory feedback in improving speech rate and intelligibility in speakers with Parkinson's disease
}

\author{
Authors: \\ Anja Lowit, PhD, Strathclyde University, UK \\ Corinne Dobinson, PhD, University Hospitals Bristol NHS Foundation Trust, UK \\ Claire Timmins, MA, Strathclyde University, UK \\ Peter Howell, PhD, University College London, UK \\ Bernd Kröger, PhD, RWTH Aachen, Germany
}

Correspondence Address:

Anja Lowit $\mathrm{PhD}$

Division of Speech and Language Therapy

Dept of Educational and Professional Studies

Strathclyde University

76 Southbrae Drive

Glasgow G13 1PP

UK

Tel 44-141-9503531

Fax 44-141-9503762

e-mail: a.lowit@strath.ac.uk

Running Head: Treatment efficacy in PD

Keywords: Parkinson's disease, altered auditory feedback, rate reduction, treatment effectiveness 


\section{Abstract}

Communication problems are a frequent symptom for people with Parkinson's disease (PD) which can have a significant impact on their quality of life. Deciding on the right management approach can be problematic though, as, with the exception of LSVT ${ }^{\circledR}$, very few studies have been published demonstrating the effectiveness of treatment techniques. The aim of this study was to compare traditional rate reduction methods with altered auditory feedback (AAF) with respect to their effectiveness to reduce speech rate and improve intelligibility in speakers with PD. Ten participants underwent both types of treatments in once weekly sessions for 6 weeks. Outcomes measures were speech rate for passage reading as well as intelligibility on both a passage reading and a monologue task. The results showed that as a group, there was no significant change in either speech rate or intelligibility resulting from either treatment type. However, individual speakers showed improvements in speech performance as a result of each therapy technique. In most cases, these benefits persisted for at least 6 months post-treatment. Possible reasons for the variable response to treatment, as well issues to consider when considering using AAF devices in treatment are discussed. 


\section{Introduction}

Loss of speech intelligibility is one of the major concerns of people with Parkinson's disease (PwPD) (Miller, Noble, Jones, \& Burn, 2006). The main changes in speech that are frequently described in the literature are reductions in vocal loudness, articulatory deficits and changes in speech rate. Most of the medical treatments available for Parkinson's disease (PD) show little improvement for speech compared to gross motor movements (Ramig, Fox \& Sapir, 2004). Treatment for speech impairments is thus still largely based on behavioural techniques. Amongst these, the Lee Silverman Voice Treatment $\left(\mathrm{LSVT}^{\circledR}\right)$ is a treatment programme that has proved to be highly effective in addressing loudness deficits (Ramig et al., 2001) with carryover to other features of PD speech disturbance such as articulatory deficits (Dromey, Ramig \& Johnson, 1995; Ramig et al., 2004). However, although efficacy studies included participants with a range of dysarthria severities, anecdotal evidence suggests that clinicians often perceive this treatment as being more appropriate for clients at the milder end of the severity spectrum due to the physical and cognitive demands associated with the treatment regime. Treatment for clients with moderate to severe dysarthria thus still relies on rate control techniques to improve a speaker's intelligibility. A number of strategies for rate reduction are described in the literature, such as pacing by finger tapping and using a pacing board or a metronome (Yorkston, Beukelman, Strand, \& Bell, 1999). Less impaired speakers are frequently asked to pace themselves without external aids. Although a number of case studies suggest that such techniques can be useful (Hammen, Yorkston, \& Minifie, 1994; Helm, 1979; Le Dorze, Dionne, Ryalls, Julien, \& Ouellet, 1992; Yorkston, Hammen, Beukelman, \& Traynor, 1990), there is no conclusive evidence for the effectiveness of rate reduction therapy in speakers who have $\mathrm{PD}$, particularly in relation to long term effects and carry over into everyday speech (Deane, Whurr, Playford, Ben-Shlomo, \& Clarke, 2001a, 2001b). In addition, the relationship between a reduction in speech rate and intelligibility is 
not always straightforward (Van Nuffelen, De Bodt, Wuyts, \& Van de Heyning, 2009; Van Nuffelen, De Bodt, Vanderwegen, Van de Heyning, Wuyts, 2010).

Altered auditory feedback (AAF) is an alternative method to traditional rate control techniques which can be used to help reduce speaking rate. The method was originally developed for people who stutter (PwS). The speaker wears a device through which they hear their speech in an altered fashion. This disrupts the normal auditory feedback loop which causes the speaker to slow down. There are several types of AAF: delayed auditory feedback (DAF) delivers the speech signal to the speaker after a short delay (usually between 50 and $200 \mathrm{~ms}$ ); frequency shifted feedback (FSF) delivers the speech signal in real time but with an altered pitch (up to 1 octave up or downward shift); and masking blocks out the auditory feedback signal. In addition, DAF and FSF can be used in combination with each other. Initial reports on DAF's effects in PwPD were published in the 1980s and 1990s (Adams, 1994; Downie, Low, \& Lindsay, 1981; Hanson \& Metter, 1983; Yorkston et al., 1999) and more recently by Van Nuffelen et al. (2009, 2010). Although these studies generally reported benefits for speech rate and intelligibility, it also became evident that speakers' responses to this approach were inconsistent, with many participants not showing the aforementioned improvements to their speech output. Some studies attempted to identify why some PwPD had a poor response to the alteration (Dagenais, Southwood, \& Mallonee, 1999; Lowit, Brendel, \& Howell, 2006; Rousseau \& Watts, 2002) but results were inconclusive.

Most investigations into AAF treatment with PwPD suffer from similar limitations to those with other treatment methods, i.e. they mainly constitute single or multiple case studies without controlled comparisons with placebo or other treatment types. There are also few indications of the long-term effectiveness of AAF devices in this speaker group. Such information would be particularly important as informal reports allude to habituation effects that might diminish any positive results AAF might have on a speaker's intelligibility (c.f. 
data on PwS by e.g. Pollard, Ellis, Finan, \& Ramig (2009)). Furthermore, previous studies generally did not report on how viable the devices were as actual therapy tools in relation to handling, maintenance and acceptance by the client.

The aims of this study were therefore (1) to compare the long-term effects of traditional rate control therapy and AAF on speaking rate and intelligibility in PwPD with a presenting dysarthria and (2) to evaluate the viability of AAF as a treatment device for everyday use.

\section{Methodology}

\section{Participants}

Ten speakers with idiopathic PD and a speech impairment severe enough to warrant treatment took part in the study. Exclusion criteria were the presence of significant dementia (MMSE score), a history of deep brain stimulation, and speech and language therapy for dysarthria symptoms during the last 12 months. In addition, the presence of speech and language problems other than those caused by PD was cause for exclusion. One exception was made where a client had an accompanying stutter. As AAF has been reported as beneficial for people who stutter, it was decided to include this person to look into the interaction of the stammer and the PD in response to AAF. Care was taken in the evaluation of the results that this speaker did not significantly influence the statistical outcome or qualitative data interpretation by running comparisons with and without his data. It was subsequently deemed appropriate to include him in all comparisons reported in this study.

Participants comprised six males (mean age 62 years; age range 52 - 67 years) and four females (mean age 62 years; age range 49 - 71 years). Their dysarthria ranged from mild to moderate-severe, as evaluated by an experienced speech and language pathologist on the 
basis of oromotor performance (DDK and maximum performance tasks), and intelligibility for single words, sentence and passage reading as well as a monologue task. Since the posttreatment assessments spanned a period of up to 18 months, it was unethical to ask speakers to remain on the same dose of medication for the full duration of the study. There were thus some changes to drug regime during the follow up period. In addition, two participants had to change their medication during one of the treatment phases. Reports in the literature on the effects of parkinsonian medication on speech are inconclusive, with some studies reporting improvements (De Letter, Santens, \& Van Borsel, 2003; Sanabria et al., 2001; Vercueil, Linard, Wuyam, Pollak, \& Benchetrit, 1999), some a status quo (De Letter, Santens, De Bodt, Boon, \& Van Borsel, 2006; Goberman, \& Coelho, 2002; Kompoliti, Wang, Goetz, Leurgans, \& Raman, 2000) and some a worsening of dysarthria symptoms (Louis, Winfield, Fahn, \& Ford, 2001, Murdoch, Chenery, Bowler, \& Ingram, 1989; Rice, Antic, \& Thompson, 2002). This suggests a highly individual response by speakers to medication and these two participants were thus not automatically excluded from the study. Instead, their speech characteristics were carefully monitored by the treating therapist who determined that no perceptually significant changes out of line with general improvement in therapy observed up to the point of medication change were evident. In addition, their profiles were examined in detail during data evaluation to ensure they did not bias the group results in any way. Table 1 provides information on the participants, with details on their symptoms, as well as device use during the treatment phases. Information on medication reflects the status at the beginning of the study. 


\section{Study design}

An alternating treatment design was employed to compare the effects of traditional ratereduction therapy (TT) and altered feedback therapy (AAF). Each participant received both types of therapy which were separated by a 6 -week no treatment period. Five speakers started with TT, the other five with AAF treatment. Participants were quasi-randomised to groups by virtue of entry to the study, i.e. they alternately started with either TT or AAF treatment. No performance variables (speech, cognition, etc.), age, gender or participant preference were thus used to determine group membership. Figure 1 details the timing of assessments and treatment periods.

Insert Figure 1 about here

\section{Intervention}

Each intervention was delivered in once weekly sessions of about 50-60 minutes duration for six weeks. This regime adhered to the treatment model that clients would typically receive from the health service in the UK (Deane et al., 2008) ${ }^{1}$. To ensure full attendance and reduce the strain on the participants, sessions were offered in their own home. This is again not unusual as part of standard NHS treatment (Deane et al., 2008).

\section{Traditional therapy $(T T)$}

TT centred on identifying the most suitable strategy for reducing speech rate (SR), i.e. increasing pauses and / or stretching out articulation. The majority of speakers opted for the pause insertion technique. Tasks followed the widely described hierarchy of complexity,

\footnotetext{
${ }^{1}$ The authors are not aware of any other formal studies into the nature of PD treatment in other parts of the world, however, anecdotal evidence suggests that the UK model is comparable to practices in a range of other countries.
} 
ranging from reading aloud short phrases to conversational speech. Phrasing exercises were integrated early on where inappropriate pause placement was used during rate reduction or during natural speech. In addition, self-appraisal skills were developed as quickly as possible through feedback and listening to recordings of their own voice. Where appropriate, other speech aspects in need of treatment, such as volume or intonational variation, were integrated into the treatment plan. Performance feedback was provided in line with motor learning principles (Maas et al., 2008; Schmidt \& Bjork, 1996; Zimmerman \& Kitsantas, 1997).

Carryover was targeted by practising more everyday type speech tasks during the therapy sessions and encouraging patients to use the strategies learned in therapy in everyday speech through homework assignments. In addition, participants were encouraged to think of a label that personally defined their speaking style when speaking at their target rate. This aimed to encapsulate their best speech in one concept, which they could then use as a cue during

practice and carryover. For example, participants labelled their reduced rate as their "laid back speech" or their "explaining voice".

\section{Altered feedback therapy (AAF)}

AAF was delivered through a choice of two devices, the Smalltalk and the School DAF (http://www.casafuturatech.com). The benefit of the Smalltalk is that it delivers both DAF and FSF. It also has a 'push to talk' facility which allows the user to activate the AAF only when they want to speak. This facility was also built into the School DAF by adding an external switch. Devices and headphones were provided to participants according to their individual needs. The choice of device depended on whether they were likely to use FSF or not. The headphones used by participants were either a Sennheiser PC131 full size binaural headset, Plantronics MX100S binaural cellphone earsets, Jabra EarWave Bud ${ }^{\mathrm{TM}}$ single earpiece headset, or a wireless Bluetooth headset (Jabra BT250v). Research has shown 
binaural input to be more effective than monaural in people who stammer (Stuart, Kalinowski, \& Rastatter, 1997). Such issues of effectiveness were balanced with acceptability of wearing the device, interference with hearing aids and the participants' ability to handle the headphones. See table 1 for participants' choice of device, headset and preferred AAF setting.

Early AAF therapy sessions were spent on determining which feedback type and setting had the best effect on rate whilst not being detrimental to naturalness and the processing of thought and speech. In most cases the AAF had an immediate effect in reducing speaking rate, and it was unnecessary to work on rate reduction strategies. Instead, intervention focused on practice using the device in various speaking tasks and situations, both during the session and at home, comparable to the therapy model for TT. In addition, intonational inflection and articulation were addressed if these were negatively influenced by the use of altered feedback.

\section{Recording and Analysis Procedures}

Recordings were obtained in participants' homes in quiet conditions. Recordings were timed to ensure that participants were performing at their optimum capacity. In cases where medication was wearing off during the recording, the assessor waited until the new dose had taken maximum effect before continuing with testing.

Participants were seated twelve inches from a Beyerdynamic Microphone M58. Recordings were made digitally using a Tascam DA-P1 digital recorder and transferred at 48k sampling rate through SPDIF to a computer. Data were subsequently analysed with the Praat analysis system (Boersma \& Weenink, 2006). 


\section{Tasks and Measures}

Data evaluation focused on two speech parameters - speech rate and intelligibility. Speech rate was chosen as outcome measure as the main effect of AAF reported in the literature is a slowing of speech. Intelligibility is one of the primary clinical outcome measures used for therapy and it was thus most suited to assess change after treatment in the current study. It was important that these outcome measures be assessed in continuous speech tasks, as AAF is known to be less effective on short stretches of speech such as single words or short sentences. The evaluation of the current participant group also suggested that considerably differences could exist between intelligibility on single words/sentences and longer connected speech task. A reading passage and a monologue were thus chosen for the purpose of the current evaluation. Details on these tasks and measures as well as the feedback conditions are as follows:

Tasks

The reading tasks consisted of the "Cherry Tree" passage (Lowit et al., 2006) which was read aloud after participants had familiarised themselves with it. It is phonetically balanced and contains a range of utterance lengths. The monologue task involved reminiscence questions such as "Tell me how transport /leisure activities / school, etc. differ today from when you were a child". Participants were asked a different stimulus question at each assessment point and for each feedback condition.

\section{Feedback Conditions}

The reading task was performed with three feedback conditions - no feedback (NF), delayed auditory feedback (DAF, 150ms delay) and frequency shifted feedback (FSF, $1 / 2$ octave upward shift, c.f. Brendel et al., 2004). In addition, all post-AAF intervention assessments 
included an additional condition with their preferred AAF setting (PF) that had been established during therapy. The monologue task was only performed in the NF and PF conditions. The order of feedback conditions and tasks was randomised for each assessment to control for fatigue effects.

In order to reflect natural carry over of the treatment strategies as much as possible, participants were not specifically instructed to reduce their speech rate during the assessments, but only to perform as best as they could.

\section{Outcome measures}

Speech rate was measured as the number of syllables produced per second including pauses. Due to a high degree of utterance and pause length in the monologue data, this measure was only calculated for the reading passage. The experimenter who processed the acoustic data was blind to treatment group, time of assessment and AAF condition. $10 \%$ of the data were re-analysed by a second experimenter. The results had a correlation coefficient of $r=.444$, $\mathrm{p}<.0005$ indicating good inter-rater agreement.

Intelligibility was measured in two different ways. For the reading passage direct magnitude estimation (DME, Whitehill, Lee, \& Chun, 2002) was employed. This helped to counteract the effects of listener familiarity with the passage. Listeners were presented with groups of 5 samples, i.e. the standard and four samples to be rated. As the purpose of this evaluation was to measure change over time rather than comparing speakers with each other, each speaker acted as their own standard. The NF condition of the first assessment was used for this 
purpose. For the monologue, listeners used a 9 point Likert scale developed by Dobinson (2007) which integrates perceptions of intelligibility ${ }^{2}$ as well as listener effort.

Ten final year SLP students acted as judges. They were familiar with dysarthric speech and were trained in DME and the Likert scale. To evaluate the AAF intervention, only the PF conditions were rated as these were most reflective of treatment outcome. Judges were blind to treatment group, assessment time and feedback condition. Inter-rater reliability for intelligibility ratings was assessed by calculating the intraclass correlation coefficient (ICC) (Shrout \& Fleiss, 1979) for the 10 listeners' scores for the first recording of the monologue. Agreement between listeners was good with a coefficient of $r=.89, \mathrm{p}<0.01$. Due to the nature of the DME rating, reliability measures could not be performed for the assessment of reading.

All procedures complied with UK National Research Ethics Service (NRES) ethical guidelines.

\section{Results}

\section{Changes over time}

To evaluate whether participants changed their speech rate or intelligibility over time, a mixed ANOVA was performed for each of these variables, with time as the within subject and therapy group (AAF or TT as first treatment) as the between subject factor. The analysis was performed with the no feedback data as these could best indicate whether any of the treatments had resulted in carry-over to naturalistic speech.

\footnotetext{
${ }^{2}$ The evaluation of the monologue task might be more accurately described as comprehensibility, as listeners were given the context of the speaker's discourse. However, the term intelligibility will be used for the remainder of this paper to simplify reference to the evaluations of the two connected speech task.
} 
Table 2 shows the group results for rate and intelligibility across time. For the reading task main effects for time were not significant for either variable (speech rate: Wilk's Lambda $=$ $.16, \mathrm{~F}(6,2)=1.73, \mathrm{p}=.411$, Partial Eta Squared $=.84$; intelligibility: Wilk's Lambda $=.39, \mathrm{~F}$ $(6,3)=.786, p=.635$, Partial Eta Squared $=.61)$, or for group $($ speech rate: $F(1,7)=.227, p=$ .648 , Partial Eta Squared $=.03$; intelligibility $\mathrm{F}(1,8)=.111, \mathrm{p}=.748$, Partial Eta Squared $=$ .01). There were also no significant interaction effects between therapy group and recording time for the reading data (speech rate: Wilk's Lambda $=.23, \mathrm{~F}(6,2)=1.09, \mathrm{p}=.551$, Partial Eta Squared $=.77$; intelligibility: Wilk's Lambda $=.18, \mathrm{~F}(6,3)=2.29, \mathrm{p}=.265$, Partial Eta Squared $=.82$ ). The statistical results thus suggest that there were no significant changes in reading without altered feedback for speech rate or intelligibility within each group, irrespective of which type of treatment participants started with. The evaluation of intelligibility in the monologue task yielded the same non-significant outcomes (interaction effect Wilk's Lambda $=.43, \mathrm{~F}(6,3)=.671, \mathrm{p}=.691$ Partial Eta Squared $=.57$; main effect for time: Wilk's Lambda $=.22, F(6,3)=1.78, \mathrm{p}=.340$, Partial Eta Squared $=.78$; main effect for group $\mathrm{F}(1,8)=.945, \mathrm{p}=.359$, Partial Eta Squared $=.11)$

\section{Insert table 2 around here}

\section{AAF treatment versus traditional therapy}

Although the ANOVA results reported above suggested that there were no significant changes over time, individual profiles suggested otherwise for at least some of the participants (see below). To evaluate whether the observed changes followed any patterns with regard to treatment type, the mean of the two pre-therapy measures was compared to the immediate post-intervention results for the NF data. For this analysis, the percentage difference between the above measurement points was calculated for each participant and 
treatment type for speech rate and intelligibility. The Wilcoxon Signed Rank Test was then applied to determine whether TT and AAF treatment differed significantly in the amount of change effected by the participants for each outcome measure (see Table 3 for group range, means and SDs). Again, no significant difference could be detected for speech rate $(p=.214)$, reading intelligibility $(\mathrm{p}=.445)$ or monologue intelligibility $(\mathrm{p}=.445)$, indicating that the two types of treatment did not affect speech output differentially when tested in the NF condition.

\section{Insert table 3 around here}

\section{Feedback conditions}

In order to investigate how the AAF settings affected speech rate and intelligibility, these variables were compared across the different feedback conditions. For intelligibility, only the NF and PF conditions had been rated. As different numbers of PF recordings were available for speakers depending on which treatment group they belonged to, NF data were only used from assessments were a PF recording had also been taken, resulting in equal numbers of data points for NF and PF conditions. Also, as the focus of this comparison was feedback type independent of treatment group or assessment point and previous analysis had already indicated that performance did not change significantly over time, the NF and PF data were pooled across time and groups, resulting in two sets of intelligibility data, NF and PF. As there were only two variables to be compared, the Wilcoxon Signed Rank Test was performed for both reading and the monologue.

Speech rate had only been analysed for the reading task, but for all four feedback conditions (NF, DAF, FSF and PF). The data were again pooled across group and time for those assessment points where all four feedback conditions were completed by the participants. A 
one-way repeated measures ANOVA was performed, with speech rate representing the dependent and the feedback type the independent variable.

The Wilcoxon Test results indicate that there was no significant difference in intelligibility between the no feedback and the preferred feedback conditions for reading $(p=.677)$ or the monologue $(\mathrm{p}=.122)$ suggesting that speakers did not benefit from AAF as a group. The speech rate comparisons between the feedback conditions, on the other hand, resulted in a significant effect for feedback type (Wilk's Lambda $=.15, \mathrm{~F}(3,18)=34.84, \mathrm{p}<.0005$, Partial Eta squared $=.85$ ), with $\mathrm{AAF}$ conditions showing slower rates than the NF condition. Bonferroni post hoc tests indicate significant differences between all feedback conditions (the significance value was below $\mathrm{p}=.002$ in all cases) with the exception of FSF and PF, which showed similar speech rates $(\mathrm{p}=.695)$. The slowest speech rate was observed with the DAF setting of $150 \mathrm{~ms}$, followed by the FSF and PF and finally the NF condition (see Table 4).

\section{Insert table 4 around here}

\section{Habituation Effects}

It became apparent at the post-intervention recordings that a number of speakers changed their preferred AAF settings over time, particularly when they had started with AAF therapy and had been using the device for some time. This suggests a certain degree of habituation to the feedback. The continued positive effects achieved by relatively changes in setting, as well as the fact that the preset DAF and FSF settings still elicited the same response observed in earlier assessments suggest that the habituation effects could be reduced or eliminated by changes to the AAF setting.

\section{Individual participant profiles}


Despite the negative outcomes from the group data, some participants did show improvements in intelligibility as a result of therapy. Given that there exists no agreed level of percentage change that is recognised as representing a clinically significant level of improvement, this conclusion was based on the observation that there was a consistent difference in performance over time and/or that changes were reflected in both the reading and the monologue data.

Four of the ten participants had higher intelligibility ratings in the no feedback condition after the first phase of therapy and were able to maintain this level across the remaining assessments, i.e. into the 6 months follow up period. Interestingly, their intelligibility improved irrespective of whether they had received AAF or TT.

Another three speakers showed improved levels of intelligibility with AAF at the preferred feedback setting, without showing improvements in their no feedback speech. Again, these improvements were maintained across all post-intervention recordings.

The remaining three speakers did not change over time and thus showed little benefit from either traditional or AAF therapy.

No pattern could be identified between improvements in speech performance and alterations in drug regime, suggesting that medication changes did not significantly affect the evaluation of treatment efficacy in the current speaker group. In addition, the participant with a stutter showed no improvement in intelligibility despite personal reports that he considered the AAF device as enhancing his communication.

The question of decline over time was considered individually as well. With the exception of two speakers, there was no clear indication that performance levels decreased significantly over the course of the study. There was also no evidence of any relationship between the severity of the participants' dysarthria or PD symptoms and the presence or rate of decline 
over the investigated period. Due to the small numbers of participants involved in these evaluations, no statistical analyses were performed to confirm these assumptions.

\section{Discussion}

This study employed an alternate treatment design to study the effects of traditional methods and AAF on rate reduction and intelligibility in a group of ten speakers with idiopathic PD. Speech rate measures revealed that participants showed no improvements over time in the self-paced NF condition, but AAF induced significantly slower speech at any given time. These rate reductions did not automatically translate into intelligibility improvements though. More generally, group statistics revealed no significant improvements after either therapy phase for intelligibility. However, individual data evaluation comparing results across tasks, feedback conditions and treatment groups revealed that a considerable number of participants did in fact benefit from both forms of treatment. They also showed that some speakers' performance declined over time, while others' remained stable. There was some evidence for habituation to AAF, particular in long-term use, but this could be counteracted by making small adjustments to the device settings.

One interesting result was the fact that intelligibility in the no feedback condition improved for some speakers after the first treatment phase, irrespective of which type of therapy they had received. This was not expected as no specific advice on speech without feedback was given during AAF treatment. The result could thus reflect a generic treatment effect, where participants generalised advice given for AAF speech, or possibly a placebo effect, in that increased attention to the participant might have resulted in improved speech output. Due to the small participant group no conclusions can be drawn about this observation at the current 
stage, but this issue should be considered in the design of future larger scale treatment evaluation studies.

\section{Traditional Therapy}

The lack of success of traditional methods was somewhat surprising as previous studies have reported success of similar methods to the current study for at least a small number of speakers, both in terms of rate reduction and intelligibility improvements (Hammen et al., 1994; Le Dorze et al., 1992; Yorkston et al., 1990).

One possible reason for this discrepancy is the post-treatment assessment method used in this study. Participants were not specifically asked to reduce their speech rate during the speaking tasks, in order to evaluate to what degree they would implement strategies learnt during therapy spontaneously in the assessment situation. Although they did not succeed in this, notes taken during the treatment sessions clearly indicate that speakers were successful in reducing rate in the clinical context. Current assessment data thus need to be interpreted as indicating that the current group did not generalise the traditional methods successfully to outside contexts, rather than not being successful at all in reducing speech rate. In addition, the individual data suggest that some speakers did in fact show some improvements in intelligibility. Individual response variability is thus an important issue to be taken into account in small scale studies such as the current.

Rate reduction methods are another factor to consider in comparing the current with previous results. The current TT treatment largely relied on self-pacing, as this was most appropriate for the participant group (only one speaker started to use an alphabet chart towards the end of the study period). This differs to the techniques used in some of the other reports in the literature, which included external pacing techniques both in treatment and for assessment. 
One other issue that could have influenced the current results is the severity of dysarthria. Those with milder severity were able to complete the treatment regime and practice slow rate with longer reading passages and spontaneous dialogues. Others, however, would have needed more than six sessions and were unable to implement the strategies in longer stretches of speech by the end of treatment. It is thus possible that those with milder severity did not feel the need to reduce rate to perform well on the tasks, and those with more severe problems were yet unable to do so. In addition, some speakers' intelligibility levels were still quite high at the start of the study, and they thus had less scope for improvement than those whose speech was impaired more severely. Another speaker related aspect that could have affected response to treatment was the cognitive state of the speaker, although no particular pattern could be detected that linked cognitive ability to therapy success in this small sample. Intensity of treatment should also be considered. The success of LSVT has focused attention on the importance of treatment frequency, which was relatively low in the current study compared to LSVT. To what degree this affected outcome cannot be assessed on the basis of the current results, but the issue should be considered in future research. Related to this is the issue of home practice. Participants were asked to indicate how much they practiced at home in this study. However, this information was insufficiently complete to be related to treatment outcome. It would be beneficial if future larger scale studies would build in ways of reliably collating such information.

A final aspect to consider in relation to treatment success is the fact that whilst few participants showed significant improvements after therapy, the performance of most speakers also did not decline to a great degree over the 18 months of the study. In the light of PD being a degenerative disease, this could potentially indicate that whilst therapy did not help speakers to improve on their current state, it might have allowed them to maintain the 
status quo for longer. As decline over time in overall PD severity was not monitored in detail, this notion has to be interpreted with caution though.

The results closely reflect those of a treatment study on participants with dysarthria following stroke (Mackenzie \& Lowit, 2007). Group results were equally inconclusive in that study despite indications that about half of the nine participants showed some communicative gain from treatment. The paper stresses the difficulty of demonstrating significant effects with small, heterogeneous participant groups, a limitation that also applies to the current investigation.

\section{AAF Therapy}

This cohort's success rate of AAF is comparable to that in the literature, i.e. around one third of participants showed benefits for rate reduction and intelligibility (Downie et al., 1981; Dagenais, Southwood \& Lee, 1998; Lowit et al., 2006). In light of the current and previous results, one can thus assume that around 25 to $30 \%$ of PwPD will show intelligibility benefits from the use of AAF. On this basis, AAF could be considered a viable treatment option for these speakers.

When assessing clients for suitability of AAF treatment, clinicians should keep in mind that current results showed that attempts to modify the participants' speech output to achieve greater intelligibility improvements were unsuccessful, i.e. a positive response to the device could not be trained during treatment. Clients should thus show an immediate beneficial response to AAF to be considered for this technique.

One advantage of the immediacy of the AAF effect is that the speed of progression through tasks is noticeably faster than for traditional treatment. In the current study, less than the 6 sessions offered would generally have sufficed, making AAF a highly cost-effective 
treatment. It should be noted though that some treatment sessions need to be provided in order to provide specific advice on usage, practice different speaking situations and establish the most appropriate AAF setting, which might differ according to speaking context.

\section{Habituation Effects}

There has been some concern amongst clinicians regarding the long-term use of AAF due to habituation. Data from the speakers who responded positively to AAF and continued using it show that the effect was maintained over this time. However, changes were made to the settings to ensure continued benefit from the use of the device, thus suggesting a certain degree of habituation to the feedback. On the positive side relatively small changes to the setting resulted in renewed speech improvements, suggesting that clients might benefit from AAF for reasonable amount of time despite habituation effects. In addition one participant reported having a 'break' from using the device now and again for a period of one or two days. This renewed the effects when he resumed using it.

\section{Device Usability}

A number of issues emerged from this study that have to be taken into account when using AAF devices with PwPD. Acceptability of using an external, visible aid is one of them. Although the actual AAF devices can be hidden from view, the headsets can not. Whilst the binaural headsets resulted in the best feedback, few speakers would wear these in public and thus opted more for the less obtrusive, monoraural headsets. A balance thus had to be struck between effectiveness and acceptability to promote device usage. Other types of AAF devices, for example the SpeechEasy system (www.speecheasy.com) that is fitted straight into the speaker's ear (Wang, Verhagen, \& de Vries, 2005) might alleviate such concerns. A more technical problem associated with headset choice was the fact that the AAF can 
interfere with hearing aids. In the case of monaural aids, a monaural headset could be used in the other ear. In the case of binaural hearing aids, the full size Sennheiser headset was able to eliminate the interference in some cases.

There were also problems associated with the handling of the devices. Originally developed for PwS, the devices do not necessarily take into account issues arising from tremor and impairment of fine motor problems experienced by the PD client population. This applied particularly to the Smalltalk device used in this study, which had very small buttons and dials to operate. Some of these limitations were overcome by making adjustments to the devices, such as adding on larger switches. The push to talk facility was valued by users as it eliminates distortions of background noise and the speech of the communication partner(s). However, there were problems associated with its use. In addition to the design issues such as participants having to locate a small button amongst other dials, operating the PTT facility also introduces an additional task that has to be coordinated with speech. One thus has to be careful that the benefits of this feature for general acceptability of using the device still outweigh any secondary problems caused by it, particularly for speakers who experience some level of cognitive decline.

In summary, the results of this study suggest that traditional as well as AAF rate reduction techniques can have long-term beneficial effects on intelligibility on a subset of PwPD. Dysarthria severity could not predict how well a speaker would respond to treatment and to what degree their performance might decline over time due to general degeneration resulting from the disease. Larger scale, well controlled studies are required of a range of rate reduction methods, combined with placebo/attention control and $\mathrm{LSVT}^{\circledR}$ treatment to identify 
the value of each type of treatment against variables such as PD severity, cognitive status and presenting symptoms of the dysarthria.

\section{Acknowledgements:}

This research was funded by Parkinson's UK. We are grateful to all those who participated in this study. 


\section{References}

Adams, S. G. (1994). Accelerating Speech in a Case of Hypokinetic Dysarthria: Descriptions and Treatment. In J. A. Till, K. M. Yorkston \& D. R. Beukelman (Eds.), Motor Speech Disorders: Advances in assessment and treatment (pp. 213-228). Baltimore, MA: Paul H. Brookes Publishing..

Boersma, P., \& Weenink, D. (2006). Praat: Doing phonetics by computer: Institute of Phonetic Sciences of the University of Amsterdam.

Brendel, B., Lowit, A. \& Howell, P. (2004). The effects of delayed and frequency shifted feedback on speakers with Parkinson's Disease. Journal of Medical Speech-Language Pathology, 12 (4), 131-138.

Dagenais, P. A., Southwood, M. H., \& Lee, T. L. (1998). Rate Reduction Methods for Improving Speech Intelligibility of Dysarthric Speakers with Parkinson's Disease. Journal of Medical Speech-Language Pathology, 6, 143-157.

Dagenais, P. A., Southwood, M. H., \& Mallonee, K. O. (1999). Assessing processing skills in speakers with PD using delayed auditory feedback. Journal of Medical SpeechLanguage Pathology, 7, 297-313.

Deane, K. H., Noble, E., Miller, N., Jones, D., Gibb, C., \& M., N. (2008). A survey of therapists' practices of speech language therapy for people with PD. Paper presented at the Advancing Parkinson's Research, PD Society UK.

Deane, K. H., Whurr, R., Playford, E. D., Ben-Shlomo, Y., \& Clarke, C. E. (2001a). Speech and language therapy for dysarthria in Parkinson's disease: a comparison of techniques. Cochrane Database of Systematic Reviews, Issue 2. Art. No.: CD002814. DOI:10.1002/14651858.CD002814.

Deane, K. H., Whurr, R., Playford, E. D., Ben-Shlomo, Y., \& Clarke, C. E. (2001b). Speech and language therapy versus placebo or no intervention for dysarthria in Parkinson's 
disease. Cochrane Database of Systematic Reviews, Issue 2. Art. No.: CD002812. DOI: $10.1002 / 14651858 . C D 002812$.

De Letter, M., Santens, P., De Bodt, M., Boon, P. \& Van Borsel, J. (2006). Levodopa induced alterations in speech rate in advanced Parkinson's disease. Acta Neurologica Belgica, $106,19-26$.

De Letter, M., Santens, P. \& Van Borsel, J. (2003). The effects of levodopa on tongue strength and endurance in patients with Parkinson's disease. Acta Neurologica Belgica, 103, 35-38.

Dobinson, C. (2007). An investigation into the use of computers for conducting home practice of speech exercises for people with dysarthria. Unpublished $\mathrm{PhD}$ Thesis. University of Newcastle upon Tyne.

Downie, A. W., Low, J. M., \& Lindsay, D. D. (1981). Speech disorder in parkinsonismusefulness of delayed auditory feedback in selected cases. British Journal of Disorders of Communination, 16, 135-139.

Dromey, C., Ramig, L. O., \& Johnson, A. B. (1995). Phonatory and articulatory changes associated with increased vocal intensity in Parkinson disease: a case study. Journal of Speech and Hearing Research, 38, 751-764.

Folstein, M. F., Folstein, S. E., \& McHugh, P. R. (1975). 'Mini-mental state': A practical method for grading the cognitive state of patients for the clinician. Journal of Psychiatry Research, 12, 189-198.

Goberman, A. M. \& Coelho, C. (2002). Acoustic analysis of Parkinsonian speech II: L-Dopa related fluctuations and methodological issues. Neurorehabilitation, 17, 247-254.

Hammen, V. L., Yorkston, K. M., \& Minifie, F. D. (1994). Effects of temporal alterations on speech intelligibility in parkinsonian dysarthria. Journal of Speech and Hearing Research, 37, 244-253. 
Hanson, W. R., \& Metter, E. J. (1983). DAF speech rate modification in Parkinson's Disease: A report of two cases. In W. Berry (Ed.), Clinical Dysarthria (pp. 231-254). Austin, Texas: Pro-Ed.

Helm, N. A. (1979). Management of palilalia with a pacing board. Journal of Speech and Hearing Disorders, 44, 350-353.

Hoehn, M. M., \& Yahr, M. D. (1967). Parkinsonism: Onset, progression and mortality. Neurology, 17, 427-442.

Howell, P. (2004). Effects of delayed auditory feedback and frequency-shifted feedback on speech control and some potentials for future development of prosthetic aids for stammering. Stammering Research, 1, 31-46.

Kompoliti, K., Wang, Q. E., Goetz, C. G., Leurgans, S. \& Raman, R. (2000). Effects of central dopaminergic stimulation by apomorphine on speech in Parkinson's disease. Neurology, 25, 458-462.

Le Dorze, G., Dionne, L., Ryalls, J., Julien, M., \& Ouellet, L. (1992). The effects of speech and language therapy for a case of dysarthria associated with Parkinson's disease. European Journal of Disorders of Communication, 27, 313-324.

Louis, E. D., Winfield, L., Fahn, S. \& Ford, B. (2001). Speech dysfluency exacerbated by levodopa in Parkinson's disease. Movement Disorders, 16, 562-565.

Lowit, A., Brendel, B., \& Howell, P. (2006). The relationship between cognitive ability and speech performance under AAF conditions. Paper presented at the Paper presentation at the Conference on Motor Speech: Motor Speech Disorders \& Speech Motor Control, March 22-26, Austin, Texas.

Maas, E., Robin, D. A., Austermann Hula, S. N., Freedman, S. E., Wulf, G., Ballard, K. J., et al. (2008). Principles of motor learning in treatment of motor speech disorders. American Journal of Speech-Language Pathology, 17, 277-298. 
Mackenzie, C., \& Lowit, A. (2007). Behavioural intervention effects in dysarthria following stroke: communication effectiveness, intelligibility and dysarthria impact. International Journal of Language and Communication Disorders, 42, 131-153.

Miller, N., Noble, E., Jones, D., \& Burn, D. J. (2006). Life with communication changes in PD. Age and Ageing, 35, 235-239.

Murdoch, B. E., Chenery, H. J., Bowler, S. \& Ingram, J. C. (1989). Respiratory function in Parkinson's subjects exhibiting a perceptible speech deficit: a kinematic and spirometric analysis. Journal of Speech and Hearing Disorders, 54, 610-626.

Pollard, R., Ellis, J. B., Finan, D., \& Ramig, P. R. (2009). Effects of the SpeechEasy on objective and perceived aspects of stuttering: A 6-month, phase I clinical trial in naturalistic environments. Journal of Speech, Language, and Hearing Research, 52, $516-533$

Ramig, L. O., Sapir, S., Countryman, S., Pawlas, A. A., O'Brien, C., Hoehn, M., et al. (2001). Intensive voice treatment (LSVT) for patients with PD: a 2 year follow up. Journal of Neurology, Neurosurgery \& Psychiatry, 71, 493-498.

Ramig, L. O., Fox, C., \& Sapir, S. (2004). Parkinson's disease: speech and voice disorders and their treatment with the Lee Silverman Voice Treatment. Seminars in Speech Language, 25, 169-180.

Rice, J. E., Antic, R. \& Thompson, P. D. (2002). Disordered respiration as a levodopainduced dyskinesia in Parkinson's disease. Movement Disorders, 17, 524-527.

Rousseau, B., \& Watts, C. R. (2002). Susceptibility of Speakers with Parkinson Disease to Delayed Feedback. Journal of Medical Speech-Language Pathology, 10, 41-49.

Sanabria, J., Ruiz, P. G., Gutierrez, R., Marquez, F., Escobar, P., Gentil, M., et al. (2001). The effect of Levodopa on Vocal Function in Parkinson's Disease. Clinical Neuropharmacology, 24, 99-102. 
Schmidt, R. A., \& Bjork, A. B. (1996). New conceptualizations of practice: Common principles in three paradigms suggest new concepts for training. In D. A. Robin, K. M. Yorkston \& D. R. Beukelman (Eds.), Disorders of Motor Speech: Assessment, Treatment and Clinical Characterization (pp. 3-23). Baltimore, MA: Paul H. Brookes Publishing.

Shrout, P. E., \& Fleiss, J. L. (1979). Interclass correlations used in assessing rater reliability. Psychological Bulletin, 86, 420-428.

Stuart, A., Kalinowski, J., \& Rastatter, M. (1997). Effect of monaural and binaural altered auditory feedback on stuttering frequency. Journal of the Acoustical Society of America, 111, 2237-2241.

Van Nuffelen, G., De Bodt, M., Wuyts, F., \& Van de Heyning, P. (2009). The effect of rate control on speech rate and intelligibility of dysarthric speech. Folia Phoniatrica Logopedica, 61, 69-75.

Van Nuffelen, G., De Bodt, M., Vanderwegen, J., Van de Heyning, P., \& Wuyts, F. (2010). Effect of Rate Control on Speech Production and Intelligibility in Dysarthria. Folia Phoniatrica et Phonetica, 62, 110 - 119.

Vercueil, L., Linard, J. P., Wuyam, B., Pollak. P., Benchetrit, G. (1999). Breathing patterns in patients with PD. Respiration Physiology, 118, 163-172.

Wang, E., Verhagen, L., \& de Vries, M. H. (2005). Using on-line altered auditory feedback treating Parkinsonian speech. Journal of the Acoustical Society of America, 118, 1965.

Whitehill, T. L., Lee, A. S., \& Chun, J. C. (2002). Direct magnitude estimation and interval scaling of hypernasality. Journal of Speech Language, and Hearing Research, 45, 8088. 
Yorkston, K. M., Beukelman, D. R., Strand, E. A., \& Bell, K. R. (1999). Management of Motor Speech Disorders in Children and Adults. Austin, Texas: Pro-Ed.

Yorkston, K. M., Hammen, V. L., Beukelman, D. R., \& Traynor, C. D. (1990). The effect of rate control on the intelligibility and naturalness of dysarthric speech. Journal of Speech and Hearing Disorders, 55, 550-560.

Zimmerman, B. J., \& Kitsantas, A. (1997). Developmental phases in self-regulation: shifting from process goals to outcome goals. Journal of Educational Psychology, 89, 29-36. 


\section{Tables \& Figures and Captions:}

Table 1: Participant profile, indicating age, gender, dysarthria symptoms and severity, PD severity (H\&Y score), cognitive score (MMSE score), treatment sequence including device setting and headset choice, and medication. All information relates to the status at the start of study.

Table 2: Group means (and SD) for speech rate and intelligibility measures for reading and monologue tasks for the no feedback (NF) condition across the seven assessment points.

Table 3: Group range, means and SDs for the percentage change from baseline to immediate post-treatment measures for speech rate and intelligibility in the reading and monologue tasks for the no feedback (NF) condition.

Table 4: Group means (and SDs) for speech rate and intelligibility across the various feedback conditions.

Figure 1: Study design indicating assessment points and treatment phases. 


\begin{tabular}{|c|c|c|c|c|c|c|c|}
\hline $\begin{array}{l}\text { Participant } \\
\text { Number }\end{array}$ & Age & Sex & Dysarthria symptoms and severity & $\begin{array}{l}\mathrm{H \& Y} \\
\text { score }\end{array}$ & $\begin{array}{l}\text { MMSE } \\
\text { score }\end{array}$ & Treatment sequence and devices & Medication \\
\hline PD1 & 49 & $\mathrm{~F}$ & $\begin{array}{l}\text { Very rapid and festinant speech / } \\
\text { Flattened inflection / Slight } \\
\text { hypernasality (3). }\end{array}$ & 1 & 29 & $\begin{array}{c}\text { AAF-TT } \\
\text { Smalltalk, 125ms delay, Jabra } \\
\text { EarWave Bud headset. }\end{array}$ & Requip 3mg tds \\
\hline PD2 & 64 & M & $\begin{array}{l}\text { Slightly rapid speech / Sometimes } \\
\text { reduced inflection (1). }\end{array}$ & 1 & 30 & $\begin{array}{c}\text { AAF-TT } \\
\text { Smalltalk, 125ms delay, Jabra } \\
\text { EarWave Bud headset. }\end{array}$ & $\begin{array}{l}\text { Entacapone } 200 \mathrm{mg} \text { daily, Madop } \\
\text { Ropinerole } 1 \mathrm{mg} \text { x } 5 \text {, Stalevo x } 2, \mathrm{~S} \\
\text { daily }\end{array}$ \\
\hline PD3 & 67 & $\mathrm{M}$ & $\begin{array}{l}\text { Rapid bursts of speech with some } \\
\text { festination / Slightly reduced } \\
\text { inflection and volume / Stammer (2). }\end{array}$ & 2 & 28 & $\begin{array}{c}\text { AAF-TT } \\
\text { Smalltalk, } 100 \text { ms delay, Jabra } \\
\text { Bluetooth headset }\end{array}$ & $\begin{array}{l}\text { Ropinerole hydrochloride } 5 \mathrm{mg} t \\
\text { hydrochloride } 1 \mathrm{mg} \text { daily; Sinemet } \\
\text { sinemet CR nocte. Amitiriptyline } 10 \mathrm{n}\end{array}$ \\
\hline PD4 & 69 & $\mathrm{M}$ & $\begin{array}{l}\text { Slightly reduced rate / Quiet voice } \\
\text { with reduced inflection / Mild } \\
\text { hypernasality (1). }\end{array}$ & 1 & 29 & $\begin{array}{c}\text { AAF-TT } \\
\text { Smalltalk, } 1 / 4 \text { octave increase, Jabra } \\
\text { Earwave Bud headset }\end{array}$ & Nil \\
\hline PD5 & 64 & $\mathrm{M}$ & $\begin{array}{l}\text { Quiet voice / Indistinct articulation / } \\
\text { Hypernasality (3). }\end{array}$ & 4 & 29 & $\begin{array}{c}\text { AAF-TT } \\
\text { School DAF, } 175 \text { ms delay, Jabra } \\
\text { EarWave Bud headset }\end{array}$ & $\begin{array}{l}\text { Apomorphine } 100 \mathrm{mg} 20 \mathrm{ml} \text { daily; } \\
(25 / 100) \text { x } 9 \text { daily; Zopiclone } \\
\text { Quetiapine } 12.5 \mathrm{mg} \text { nocte; Mado } \\
\text { 125mg daily; Diazepam } 2 \mathrm{mg} \text { nocte. }\end{array}$ \\
\hline PD6 & 71 & $\mathrm{~F}$ & $\begin{array}{l}\text { Rapid rate / Decreased inflection and } \\
\text { quiet voice (3). }\end{array}$ & 3 & 29 & $\begin{array}{c}\text { TT-AAF } \\
\text { Smalltalk, 125ms delay, Jabra } \\
\text { EarWave Bud headset. }\end{array}$ & $\begin{array}{l}\text { Sinemet plus } 25 / 100 \mathrm{mg} \times 1 \text {, Sineme } \\
\mathrm{x} 2 \text {, Risedronate Sodium } 35 \mathrm{mg} \text { x } 1 \text { we }\end{array}$ \\
\hline PD7 & 52 & $\mathrm{M}$ & $\begin{array}{l}\text { Slightly rapid speech / Quiet voice and } \\
\text { reduced inflection (2). }\end{array}$ & 2.5 & 30 & $\begin{array}{c}\text { TT-AAF } \\
\text { Smalltalk, } 90 \text { ms delay \& 1/4 octave } \\
\text { increase, Jabra EarWave Bud headset }\end{array}$ & $\begin{array}{l}\text { Sinemet Plus x1, Entacapone } 200 \mathrm{~m} \\
1.25 \mathrm{mg} \text {, Ropinerole } 8 \mathrm{mg} \text { tds. }\end{array}$ \\
\hline PD8 & 66 & $\mathrm{M}$ & $\begin{array}{l}\text { Slightly rapid speech / Quiet voice / } \\
\text { Slightly reduced inflection (2). }\end{array}$ & 3 & 29 & $\begin{array}{c}\text { TT-AAF } \\
\text { Smalltalk, } 1 / 4 \text { octave increase, } \\
\text { Sennheiser binaural headset }\end{array}$ & $\begin{array}{l}\text { Sinemet plus } 6 \text { daily, Mirapexin } 250 \\
\text { 20mg, Mirapexin } 1 \mathrm{mg} \mathrm{x} 2 \text {, Sinem } \\
\text { Glycerole trinitrate } 400 \mathrm{mcg} \text {. Rasagal }\end{array}$ \\
\hline PD9 & 63 & $\mathrm{~F}$ & $\begin{array}{l}\text { Rapid speech / Very quiet voice with } \\
\text { poor inflection / Slight hypernasality / } \\
\text { Poor breath support / Poor } \\
\text { intelligibility (4). }\end{array}$ & 5 & 29 & $\begin{array}{c}\text { TT-AAF } \\
\text { Smalltalk, } 200 \text { ms delay, Jabra } \\
\text { EarWave Bud headset. }\end{array}$ & $\begin{array}{l}\text { Sinemet plus, Domperidone } 10 \mathrm{mg} \text { ma } \\
100 \mathrm{mg} \text { mane, Thyroxine } 100 \mathrm{mcg} \mathrm{m} \\
20 \mathrm{mcg} \text { nocte, Amitriptyline } 10 \mathrm{mg} \mathrm{n} \\
\text { nocte, Amoxocylin mane }\end{array}$ \\
\hline PD10 & 63 & $\mathrm{~F}$ & Rapid speech (1). & 3 & 30 & $\begin{array}{c}\text { TT-AAF } \\
\text { Smalltalk, } 1 / 4 \text { octave increase, Jabra } \\
\text { EarWave Bud headset }\end{array}$ & $\begin{array}{l}\text { Stavelo 50/125/200 x 8, Selegiline } \\
1 \mathrm{mg} \text { tds, Madopar } 62.5 \text { as reqd. }\end{array}$ \\
\hline
\end{tabular}

Dysarthria Severity: 1 = mild, 2 = mild-moderate, 3 = moderate, 4 = moderate-severe, 5 = severe; H\&Y = Hoehn \& Yahr (1967) score, MMSE = Minimental

State Examination (Folstein, Folstein, \& McHugh, 1975), AAF = altered auditory feedback therapy; TT = traditional therapy 
Tab 1 


\begin{tabular}{|c|c|c|c|c|c|c|c|}
\hline Assessment: & 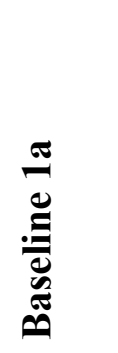 & 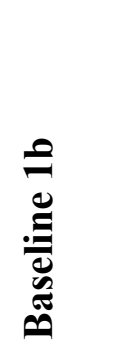 & 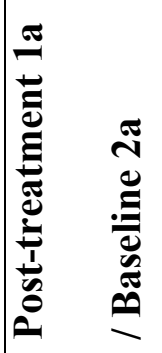 & 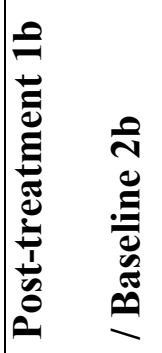 & 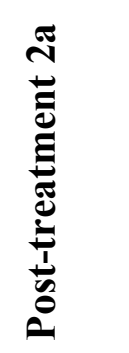 & 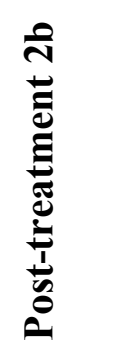 & 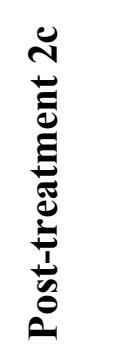 \\
\hline Speech rate: & 3.73 & 3.85 & 3.47 & 3.56 & 3.55 & 3.46 & 3.92 \\
\hline Reading & $(0.60)$ & $(0.61)$ & $(0.50)$ & $(0.43)$ & $(0.56)$ & $(0.76)$ & $(0.24)$ \\
\hline Intelligibility: & 100 & 99 & 110 & 109 & 116 & 116 & 114 \\
\hline Reading & $(0)$ & (20) & (11) & (16) & (15) & (20) & (31) \\
\hline Intelligibility: & 7.1 & 7.0 & 7.3 & 7.1 & 7.0 & 7.1 & 6.9 \\
\hline Monologue & (2.1) & $(2.1)$ & $(2.0)$ & (2.3) & $(2.0)$ & (1.9) & (2.3) \\
\hline
\end{tabular}

Speech rate: syllables/second, Reading intelligibility: DME rating, Monologue Intelligibility: 0-9 Likert scale. NB: The DME rating for Reading Intelligibility at Baseline 1a was used as the evaluation standard, so each speaker received a value of 100 for this sample.

Tab 2 


\begin{tabular}{|l|l|l|l|}
\hline Treatment Type: & Reading: & Reading: & Monologue: \\
\hline TT treatment & Range: $-5.6-+21.5$ & Range: $-77-+15$ & Range: $-8.4-+17.1$ \\
& Mean: 6.2 & Mean: -16.2 & Mean: 1.2 \\
& SD: 9.9 & SD: 30.85 & SD: 7.2 \\
\hline AAF treatment & Range: $-17.9-+16.4$ & Range: $-47-+23$ & Range: $-33.3-+10.0$ \\
& Mean: -1.7 & Mean: -8.1 & Mean: -6.0 \\
& SD: 9.6 & SD: 20.42 & SD: 13.1 \\
\hline
\end{tabular}

NB: Negative values signal an increase in speech rate/intelligibility from baseline to post-treatment assessment.

Tab 3 


\begin{tabular}{|l|c|c|c|c|}
\hline Feedback Type & NF & PF & DAF & FSF \\
\hline Speech Rate: & 3.6 & 3.2 & 2.7 & 2.9 \\
Reading & $(0.2)$ & $(0.2)$ & $(0.3)$ & \\
\hline Intelligibility: & 113 & 110 & & \\
Reading & $(20.8)$ & $(19.8)$ & & \\
\hline Intelligibility: & 7 & 8 & & \\
Monologue & $(1.8)$ & $(1.8)$ & & \\
\hline
\end{tabular}

Speech rate: syllables/second, Reading intelligibility: DME rating, Monologue Intelligibility: 0-9 Likert scale; $\mathbf{N F}-$ no feedback, $\mathbf{P F}=$ preferred feedback, $\mathbf{D A F}=$ delayed auditory feedback, $\mathbf{F S F}=$ frequency shifted feedback.

Tab 4 


\begin{tabular}{|c|c|c|c|c|c|c|c|c|c|c|c|}
\hline Group 1 & & & \multicolumn{2}{|c|}{ AAF treatment } & & \multicolumn{2}{|c|}{ TT treatment } & & & & \\
\hline Group 2 & & & \multicolumn{2}{|c|}{ TT treatment } & & \multicolumn{2}{|c|}{ AAF treatment } & & & & \\
\hline & $\uparrow$ & $\begin{array}{c}\text { No } \\
\text { treatment }\end{array}$ & $\uparrow$ & $\uparrow$ & $\begin{array}{c}\text { No } \\
\text { treatment }\end{array}$ & 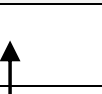 & $\uparrow$ & $\begin{array}{c}\text { No } \\
\text { treatment }\end{array}$ & $\uparrow$ & $\begin{array}{c}\text { No } \\
\text { treatment }\end{array}$ & $\uparrow$ \\
\hline 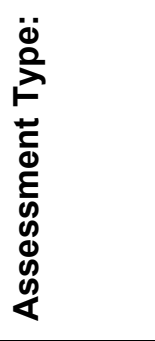 & 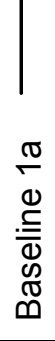 & & 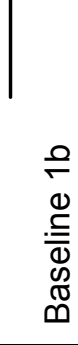 & 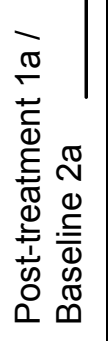 & & 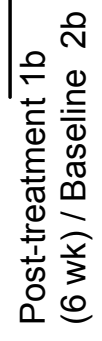 & 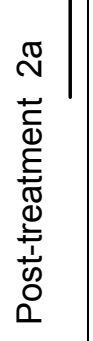 & & 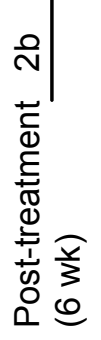 & & 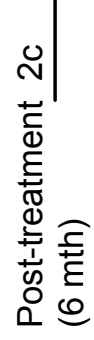 \\
\hline Week: & 0 & & 6 & 12 & & 18 & 24 & & 30 & & 48 \\
\hline
\end{tabular}

Fig 1 